
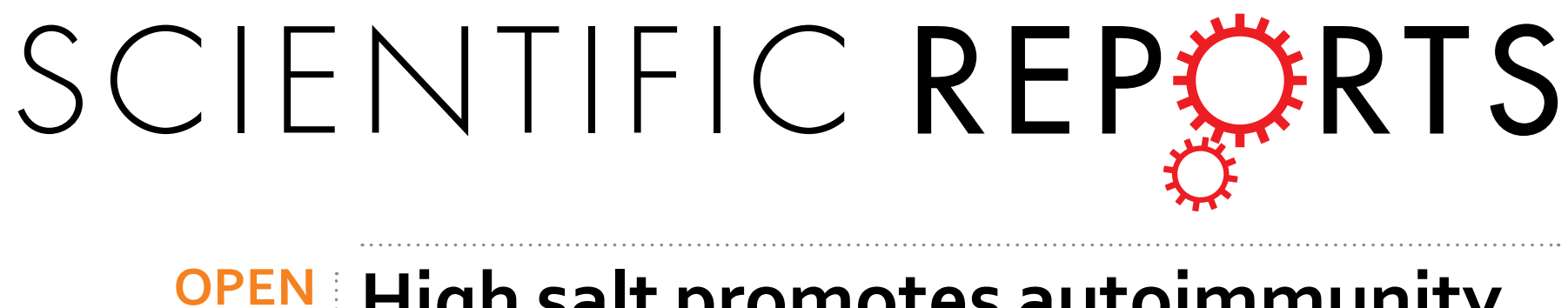

\title{
High salt promotes autoimmunity by TET2-induced DNA demethylation and driving the differentiation of Tfh cells
} Received: 04 April 2016 Accepted: 31 May 2016

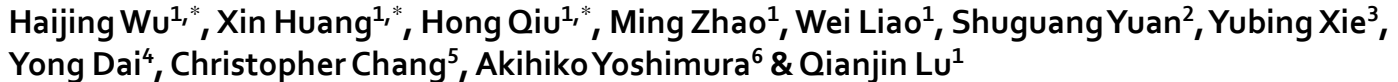

Follicular helperT cells ( $\mathrm{Tfh}$ ) have been well documented to play a critical role in autoimmunity, such as systemic lupus erythematosus (SLE), by helping B cells. In this study, high salt (sodium chloride, $\mathrm{NaCl}$ ), under physiological conditions, was demonstrated to increase the differentiation of Tfh. A high-salt diet markedly increased lupus features in MRL/lpr mice. The mechanism is $\mathrm{NaCl}$-induced DNA demethylation via the recruitment of the hydroxytransferase Ten-Eleven Translocation 2 (TET2). Gene silencing of TET2 obviously diminished $\mathrm{NaCl}$-induced $\mathrm{Tfh}$ cell polarization in vitro. In addition, the gene expression of sh2d1a, map3k1, spn and stat5b was enhanced after $\mathrm{NaCl}$ treatment, consistent with the findings in lupus $\mathrm{CD4}^{+} \mathrm{T}$ cells. However, only spn was directly regulated by TET2, and spn was not the sole target for $\mathrm{NaCl}$. Our findings not only explain the epigenetic mechanisms of high-salt induced autoimmunity but also provide an attractive molecular target for intervention strategies of patients.

Systemic lupus erythematosus (SLE) is a multi-systemic, autoimmune disease that predominately affects women (female to male ratio is 9 to 1 ) during their reproductive years ${ }^{1}$. SLE is characterized by the presence of a diverse set of autoantibodies in the circulating blood of affected patients ${ }^{2}$ and auto-reactive $\mathrm{T}$ and B lymphocytes $\mathrm{s}^{3,4}$. Although the direct cause of SLE remains unidentified, many factors are believed to contribute to immune dysregulation in SLE, including genetic susceptibility, hormones and environmental factors ${ }^{5}$. SLE occurs when an individual with genetic susceptibility to lupus encounters certain variable environmental triggers, which may include diet, toxins, exercise and others.

Increased salt (sodium chloride, $\mathrm{NaCl}$ ) uptake was recently revealed to promote experimental autoimmune encephalomyelitis (EAE) via the induction of pathogenic Th17 cells ${ }^{6}$. This effect of $\mathrm{NaCl}$ occurs via activation of the MAPK/p30 pathway ${ }^{6}$. A prior study by the same group indicated that excess $\mathrm{NaCl}$ uptake influences the innate immune system, primarily leading to changes in the activation status of macrophages ${ }^{7}$, and may even affect the suppressive capacity of regulatory T cells ${ }^{8}$. Therefore, one of the aims of the present study is to investigate whether $\mathrm{NaCl}$ also affects other immune cells and contributes to the development of SLE.

Many environmental factors have been implicated as triggers of SLE, and it is increasingly apparent that these environmental insults exert their effects via epigenetic mechanisms. External factors which can act synergistically include dietary deficiencies in Vitamin B, folate, methionine (Met), choline and $\mathrm{Zn}^{9}$, all of which are necessary to maintain normal DNA methyltransferase 1 ( DNMT1) levels ${ }^{10}$. We have previously demonstrated the critical role of DNA hypomethylation in SLE pathogenesis ${ }^{11-14}$. Therefore, DNA methylation is considered one of the primary mechanisms of environment-triggered immune disorders.

${ }^{1}$ Department of Dermatology, Hunan Key Laboratory of Medical Epigenomics, Second Xiangya Hospital, Central South University, Changsha, Hunan, China. ${ }^{2}$ Department of Nephrology, Second Xiangya Hospital, Central South University, Changsha, Hunan, China. ${ }^{3}$ Changsha Blood Center, Changsha, Hunan, China. ${ }^{4}$ Clinical medical research center, the Second Clinical medical college of Jinan University (Shenzhen People's Hospital), Shenzhen, Guangdong, China. ${ }^{5}$ Division of Rheumatology, Allergy and Clinical Immunology, University of California at Davis, Davis, USA. ${ }^{6}$ Department of Microbiology and Immunology, Keio University School of Medicine, Tokyo, Japan. *These authors contributed equally to this work. Correspondence and requests for materials should be addressed to Q.L. (email: qianlu5860@gmail.com) 
A

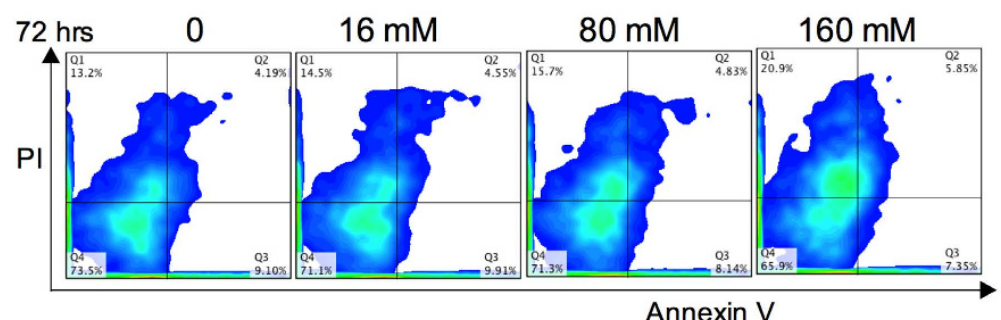

B

C
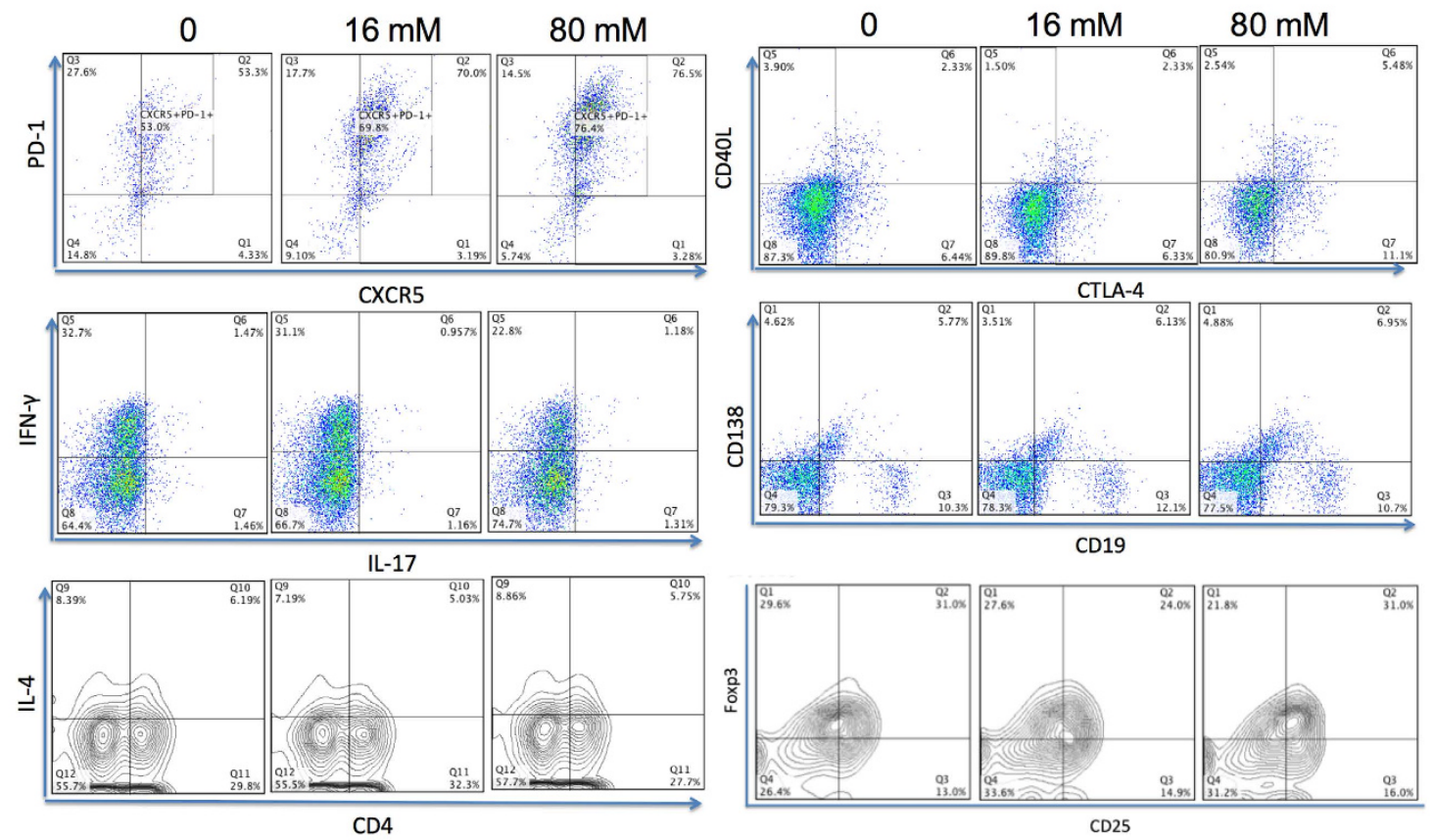

D
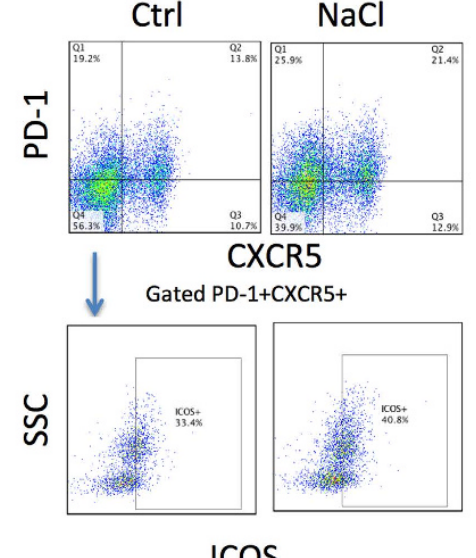

E

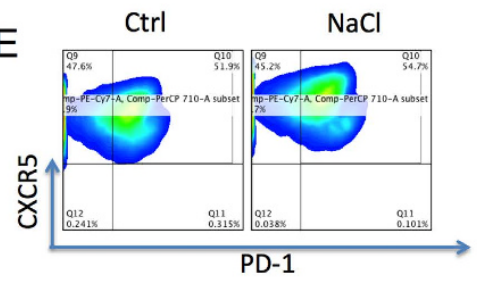

$\mathrm{F}$

G

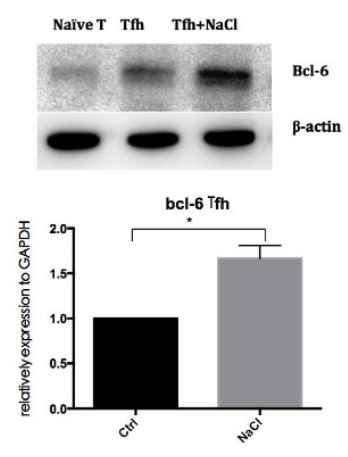

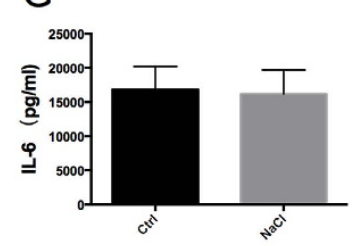

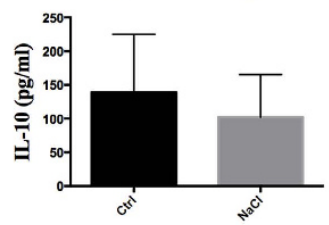

Figure 1. $\mathrm{NaCl}$ increases the frequency of $\mathrm{Tfh}$ cells among PBMCs $\mathrm{CD4}^{+} \mathrm{T}$ cells and promotes $\mathrm{Tfh}$ cell differentiation. Normal PBMCs, $\mathrm{CD}^{+} \mathrm{T}$ or naïve $\mathrm{T}$ cells were cultured with $\mathrm{NaCl}$, and cell surface markers and intracellular molecules were measured by flow cytometry, western blot, qPCR and Bio-plex. (A) Apoptosis of PBMCs treated with $\mathrm{NaCl}(0,16 \mathrm{mM}, 80 \mathrm{mM}$, and $160 \mathrm{mM})(\mathrm{n}=3)$. (B) Expression of PD-1, CXCR5, IFN- $\gamma$, and IL-4 gated on $\mathrm{CD} 4{ }^{+} \mathrm{T}$ cells in the presence of anti-CD3 and $\mathrm{CD} 28$ stimulation with or without $\mathrm{NaCl}$ $(\mathrm{n}=3)$. (C) Expression of CD40L, CTLA-4, CD25 and Foxp3 gated on CD4 ${ }^{+} \mathrm{T}$ cells with or without $\mathrm{NaCl}$ $(\mathrm{n}=3)$. (D) The expression of PD-1, CXCR5, and ICOS on $\mathrm{CD} 4^{+} \mathrm{T}$ cells with or without $\mathrm{NaCl}$ and $\mathrm{mRNA}$ 
level of BCL-6 $(n=6)$. (E) The expression of ICOS and PD-1 on Day 7 of Tfh cell differentiation and cells were gated on $\mathrm{CD}^{+} \mathrm{CXCR}^{+}(\mathrm{n}=3)$. (F) Western blot and qPCR data for Tfh differentiation on Day 7 showing the protein and mRNA levels of BCL-6 $(\mathrm{n}=3)$. (G) IL-6 and IL-10 production levels from CD4 + T cells cultured without anti-CD3 and CD28 stimulation $(n=3)$. All flow cytometry figures represent one set of experiments, and each experiment was repeated at least three times on different individuals. Horizontal bars represent the mean \pm SEM. $* p<0.05$.

The effect of $\mathrm{NaCl}$ on immune cells, including peripheral blood mononuclear cells (PBMCs), CD4 ${ }^{+} \mathrm{T}$ cells, and B cells was evaluated in this study. Surprisingly, among PBMCs, NaCl had no significant effect on Th1, Th2, Th17 and Treg cells but significantly increased the frequency of Tfh cells and promoted Tfh cell differentiation from naïve T cells. Tfh cells are a T helper-cell subset which specializes in in stimulating providing help to B cells in germinal centers (GC). Tfh cells also play a key role in GC formation and the selection of high-affinity B cells in GCs ${ }^{15-17}$. Because SLE is a multi-systemic, autoimmune disease characterized by the presence of a diverse set of autoantibodies in the circulating blood of affected patients ${ }^{2}$ and auto-reactive T and B lymphocytes ${ }^{3,4}$, it would be logical that Tfh cells might contribute to the pathogenesis of SLE. Tfh cells are distinguished by surface markers such as CXCR5, PD-1, ICOS and the specific transcription factor BCL-6. CXCR5 guides Tfh cell migration into B-cell follicles, and ICOS delivers activation signals to CD4 ${ }^{+} \mathrm{T}$ cells when these cells interact with antigen-presenting cells (dendritic cells and B cells) expressing ICOS ligand. ICOS signaling is essential for Tfh cell differentiation ${ }^{18}$. PD-1 is highly expressed on Tfh cells and serves as a negative regulator of Tfh cell differentiation ${ }^{15-17,19}$. We have observed a higher percentage of $\mathrm{CD} 4^{+} \mathrm{CXCR} 5^{+} \mathrm{PD}-1^{+}$cells in peripheral blood from SLE patients and $\mathrm{CD} 4{ }^{+} \mathrm{CXCR} 5^{\text {hi }} \mathrm{PD}-1^{\text {hi }} \mathrm{Bcl}-6^{+}$frequency was positively correlated with SLEDAI, negatively correlated with ESR and C4 (unpublished data), which is consistent with the results of other studies ${ }^{20-22}$, indicating a critical role of Tfh cells in SLE.

In addition, high-salt diet accelerated the lupus like symptoms on lupus prone (MRL/lpr) mice. However, the effect of a high-salt diet was not as obvious in Balb/c and MRL/mpj mice. Moreover, NaCl-treated CD4 ${ }^{+} \mathrm{T}$ cells displayed DNA hypomethylation and increased DNA hydroxymethylation, potentially correlating with higher levels of the hydroxyltransferases TET2 and TET3. Enrichment of TET2 on spn and stat5b was observed after the addition of $\mathrm{NaCl}$. Silencing TET2 reduced spn gene expression and inhibited Tfh cell differentiation. For the first time our study sheds light on the importance of $\mathrm{NaCl}$ in immune disorders and reveals the role of epigenetics in the underlying mechanisms.

\section{Results}

$\mathrm{NaCl}$ increases the frequency of Tfh cells in PBMCs and $\mathrm{CD}_{4}{ }^{+} \mathrm{T}$ cells and promotes Tfh cell differentiation. To explore the optimal dose for culturing, increasing doses $(0,16 \mathrm{mM}, 80 \mathrm{mM}, 160 \mathrm{mM})$ of $\mathrm{NaCl}$ were added to normal PBMCs for $72 \mathrm{hr}$., and apoptosis was evaluated. As shown in Fig. 1A, $16 \mathrm{mM}$ and $80 \mathrm{mM}$ $\mathrm{NaCl}$ had no significant effect on cell apoptosis, and $160 \mathrm{mM} \mathrm{NaCl}$ did not affect cell viability but we observed a severe cell death at $800 \mathrm{mM}$ (data not shown). In our preliminary study, $\mathrm{NaCl}$ concentration less than $16 \mathrm{mM}$ showed no significant effect on $\mathrm{CD}^{+} \mathrm{T}$ cells, while $80 \mathrm{mM}$ generated stronger stimulation of Tfh cells. In addition, it is reported that $160 \mathrm{mM}$ to $260 \mathrm{mM} \mathrm{Na}^{+}$levels has been found in interstitium and lymphoid tissue $\mathrm{m}^{7,23}$, although normally $\mathrm{Na}^{+}$in plasma is $140 \mathrm{mM}$. This is the rationale for the choice of 80 millimolar for the bulk of the experiments. Plus with the standard culture medium, which $\mathrm{Na}^{+}$level is approximate $140 \mathrm{mM}$, the final concentration of $\mathrm{NaCl}$ is $220 \mathrm{mM}$.

To determine which $\mathrm{T}$ helper cell subset is affected by $\mathrm{NaCl}$, $\mathrm{PBMCs}$ were treated with or without $\mathrm{NaCl}$ in the presence or absence of anti-CD3 and CD28 stimulation. Surprisingly, NaCl had no significant effect on IL-17, IFN- $\gamma$, and IL-4 production (Fig. 1B) but increased the frequency of Tfh cells $\left(\mathrm{CD} 4^{+} \mathrm{PD}-1^{+} \mathrm{CXCR} 5^{+}\right)$. Moreover, $\mathrm{NaCl}$ had little effect on the percentage of Treg $\left(\mathrm{CD} 4^{+} \mathrm{CD} 25^{+} \mathrm{Foxp}^{+}\right)$and plasma cells $\left(\mathrm{CD} 19^{+} \mathrm{CD} 138^{+}\right)$, and slightly increased the expression of CD40L and CTLA- 4 on $\mathrm{CD}^{+} \mathrm{T}$ cells (Fig. 1C). To further investigate the effect of $\mathrm{NaCl}$ on $\mathrm{CD}^{+}{ }^{+} \mathrm{T}$ cells and $\mathrm{T}$ cell differentiation, $\mathrm{NaCl}$ was added to $\mathrm{CD} 4^{+} \mathrm{T}$ cell cultures for $48 \mathrm{hr}$ and naïve $\mathrm{T}$ cells during Tfh differentiation. As shown in Fig. $1 \mathrm{D}, \mathrm{NaCl}$ significantly increased the frequency of the CD4 ${ }^{+} \mathrm{PD}-$ $1^{+} \mathrm{CXCR}^{+}$and $\mathrm{CD} 4^{+} \mathrm{PD}-1^{+} \mathrm{CXCR}^{+}{ }^{+} \mathrm{ICOS}^{+}$populations on $\mathrm{CD} 4^{+} \mathrm{T}$ cells and the mRNA level of BCL- 6 , the key transcription factor in $\mathrm{Tfh}$ cells ${ }^{24}$. In addition, $\mathrm{NaCl}$ increased $\mathrm{Tfh}$ cells during Tfh cell differentiation from naïve T cells (Fig. 1E,F). The percentage of $\mathrm{CD} 4^{+} \mathrm{PD}-1^{+} \mathrm{CXCR}^{+}$was much higher during Tfh differentiation (Fig. 1E) than in total CD4 ${ }^{+} \mathrm{T}$ cells (Fig. 1D) due to the Tfh cell polarization condition (IL-6, TGF- $\beta$, IL-1 $\beta$ and IL-23). Cytokine production in the supernatant from $\mathrm{CD} 4^{+} \mathrm{T}$ cell cultures was measured by Bio-plex; no effect of $\mathrm{NaCl}$ was observed, and most cytokines were under detectable (Fig. 1G). These findings suggest that $\mathrm{NaCl}$ increases Tfh cells among PBMCs and $\mathrm{CD} 4^{+} \mathrm{T}$ cells and promotes Tfh cell differentiation.

High salt diet accelerates the progression of lupus in MRL/Ipr mice but not MRL/mpj and Balb/c mice. Based on the effects of $\mathrm{NaCl}$ on human $\mathrm{CD} 4^{+} \mathrm{T}$ cells, we next investigated the effect of a high-salt diet on the mouse in vivo system. As shown in Fig. 2, a high-salt diet significantly increased mortality and accelerated the onset of lupus nephritis (Fig. 2A), as evidenced by higher levels of proteinuria (Fig. 2B), plasma levels of anti-dsDNA IgG antibodies and IgG1 (Fig. 2C), lupus-like histological alterations (Fig. 2E), and C3a and IgG deposits in glomeruli (Fig. 2F). A trend of higher frequency of Tfh cells was also observed in splenocytes (Fig. 2D). These results indicate that $\mathrm{NaCl}$ can accelerate lupus symptoms in lupus-susceptible mice and suggest that an increase in Tfh cells may be a potential mechanism.

To further examine the impact of a high-salt diet on normal mice, twenty 12 week-old Balb/c mice were randomly assigned to 2 groups and received normal chow and tap water ad libitum (control group) or sodium-rich 


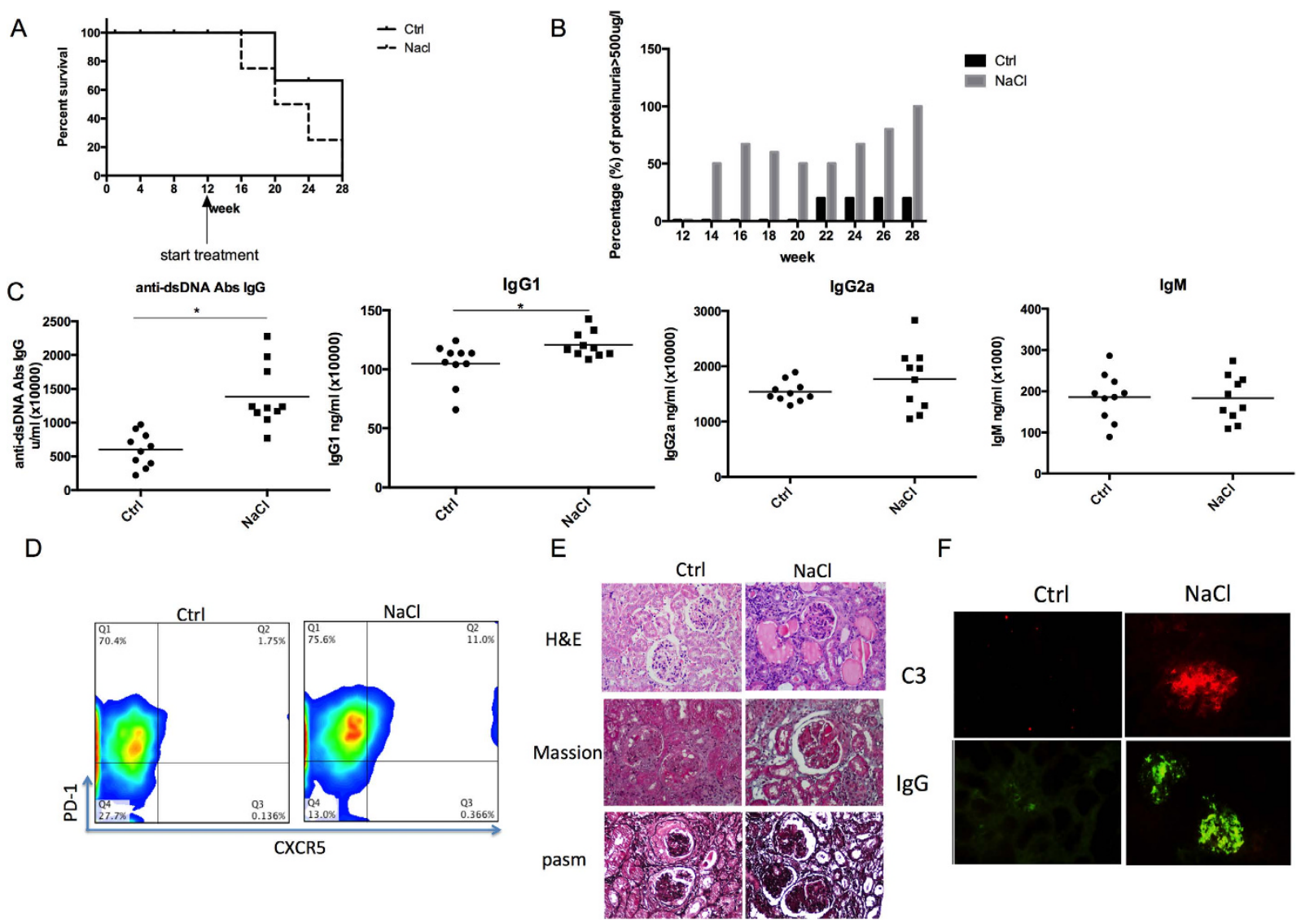

Figure 2. $\mathrm{NaCl}$ accelerates the progression of lupus in MRL/lpr mice. Twenty 12 -week old MRL/lpr mice were randomly divided into 2 groups that received normal chow and tap water ad libitum (control group) or sodium-rich chow containing $4 \% \mathrm{NaCl}$ and tap water containing $1 \% \mathrm{NaCl}$ ad libitum (high-salt group) ${ }^{6}$ until 28 weeks of age. (A) Survival of mice. (B) Proteinuria. (C) Plasma levels of anti-dsDNA antibodies IgG, IgG1, IgG2a and IgM. (D) Expression of PD-1 and CXCR5 in CD4 ${ }^{+}$splenocytes in mice treated with or without $\mathrm{NaCl}$. (E) Renal histological analysis by H\&E, Masson and pasm staining. (F) Immunofluorescence histopathological analysis of $\mathrm{C} 3 \mathrm{a}$ and IgG deposits in glomeruli. All flow cytometry figures represent one set of experiments, and each experiment was repeated at least 6 times on different mice. The horizontal bars represent the mean \pm SEM.

chow containing $4 \% \mathrm{NaCl}$ and tap water containing $1 \% \mathrm{NaCl}$ ad libitum (high-salt group) until 28 weeks of age. The high-salt diet failed to induce or promote the onset of lupus in Balb/c mice. These mice did not develop proteinuria (Fig. 3A), but did show slightly increased IgG deposits in the glomeruli (Fig. 3B) and enhanced the percentage of Tfh cells in splenocytes (Fig. 3C, $p>0.05$ ), and only slight increased anti-dsDNA antibodies (Fig. 3D). Interestingly, the high-salt diet also failed to induce lupus-like symptoms in MRL/mpj mice $(n=20)$; no obvious increased proteinuria or anti-dsDNA antibodies were observed (Fig. 3E). However loss of body weight and slight renal damage were observed (data was not shown). These findings indicate that a high-salt diet may promote lupus in SLE-susceptible mice but cannot induce SLE in normal mice.

$\mathrm{NaCl}$ induces DNA hypomethylation of $\mathrm{CD}^{+}{ }^{+} \mathrm{T}$ cells and enhances the expression of the hydroxyltransferases TET2 and TET3. To explore the mechanisms of enhancement of Tfh cells in human CD4 ${ }^{+} \mathrm{T}$ cells, we measured DNA methylation and DNA hydroxymethylation levels on normal $\mathrm{CD} 4^{+} \mathrm{T}$ cells in the presence or absence of $\mathrm{NaCl}$. As shown in Fig. 4A,B, high-salt-treated $\mathrm{CD} 4^{+} \mathrm{T}$ cells exhibited significant DNA hypomethylation and increased hydroxymethylation levels, as confirmed by both flow cytometry and DNA dot plots. These phenomena might be due to an increase in the hydroxyltransferases TET2 and TET3 in the presence of salt (Fig. 4C), specially a dramatic increased level in TET2 ( 3 fold). The gene expression of DNMT1 was also increased in high-salt-treated CD4 ${ }^{+} \mathrm{T}$ cells, whereas the differences in DNMT3A and DNMT3B expression levels were not detectable. These data indicate that DNA methylation modification may be involved in the induction of Tfh cells by $\mathrm{NaCl}$.

TET2 plays an important role in Tfh cell differentiation and $\mathrm{NaCl}$-induced Tfh cell promotion. To determine if TET2 participates in Tfh cell differentiation, the mRNA and protein levels of TET2 were determined. As shown in Fig. 5C, compared with normal naïve T cells, Tfh cells on Day 7 exhibited a significant increase in TET2 protein levels that was further enhanced by the addition of $\mathrm{NaCl}$. Moreover, the mRNA level of 


\section{A}

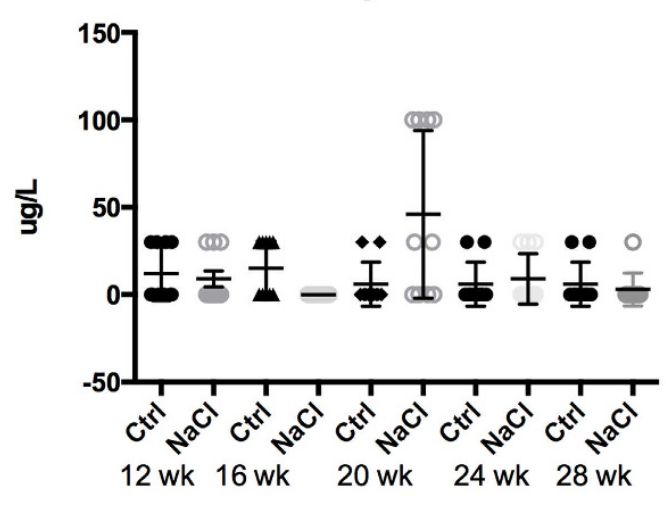

B

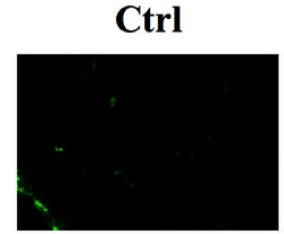

$\mathbf{H} \& \mathbf{E}$

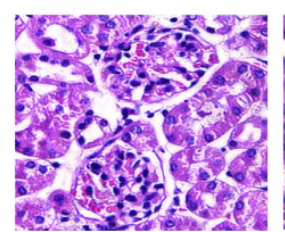

$\mathrm{NaCl}$
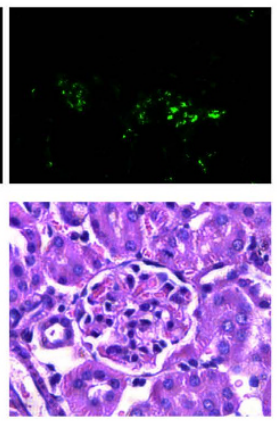

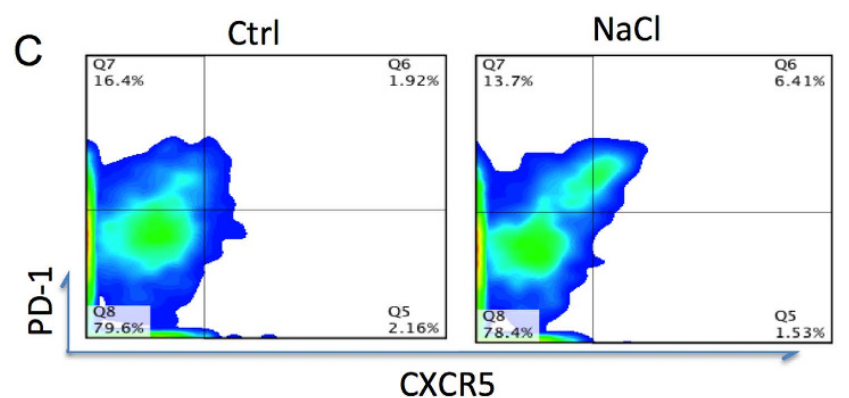

balb/c

$\mathrm{D}$

도을

$\mathrm{E}$
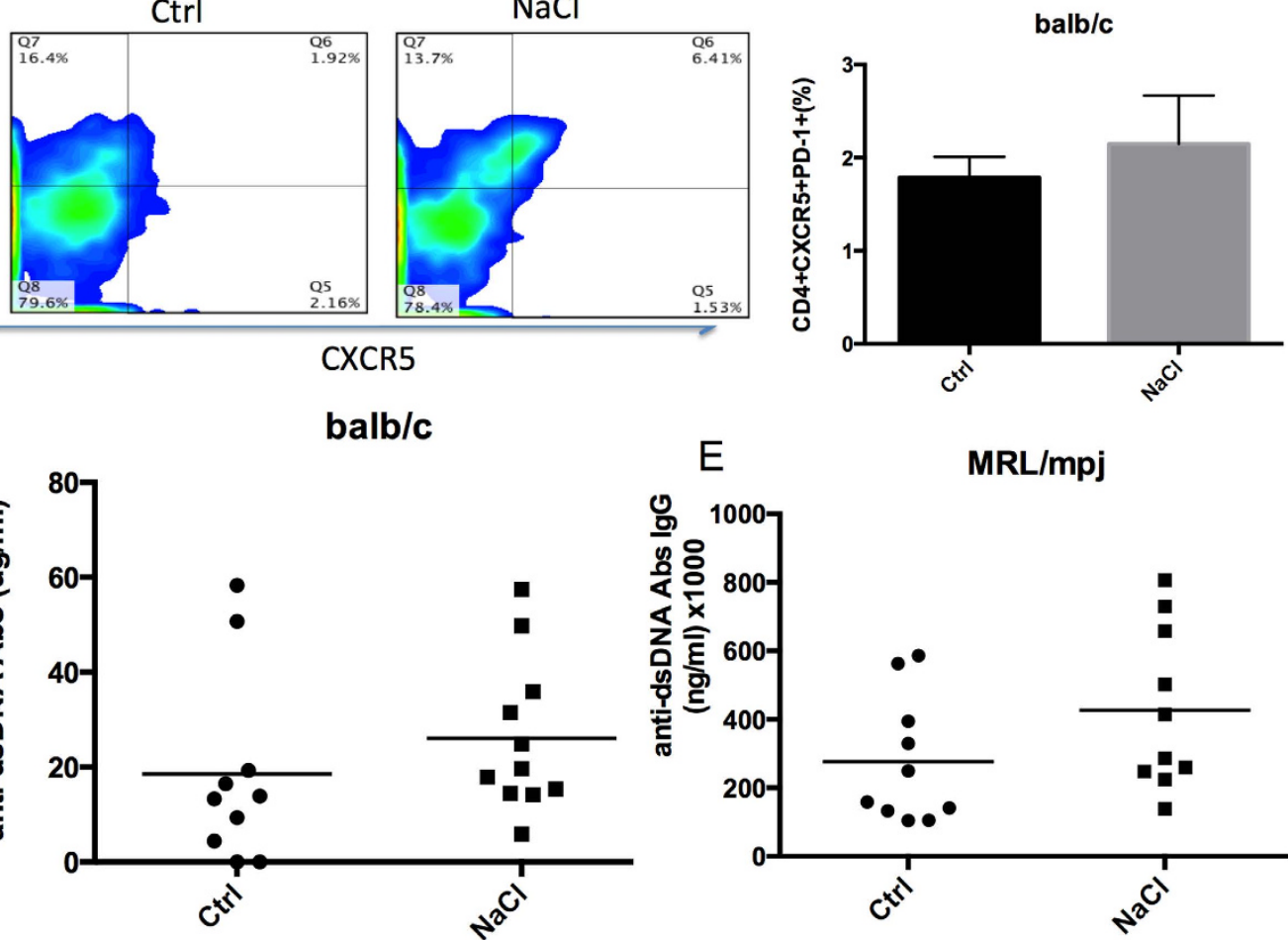

MRL/mpj

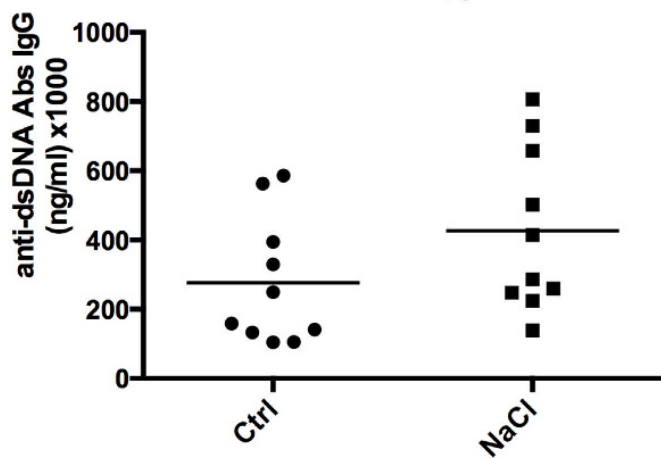

Figure 3. $\mathrm{NaCl}$ does not induce or promote lupus-like symptoms in Balb/c and $\mathrm{MRL} / \mathrm{mpj}$ mice. Twenty 12 -week old Balb/c mice were randomly assigned to 2 groups that received normal chow and tap water ad libitum (control group) or sodium-rich chow containing $4 \% \mathrm{NaCl}$ and tap water containing $1 \% \mathrm{NaCl}$ ad libitum (high-salt group) until 28 weeks of age. (A) Proteinuria levels. (B) Immunofluorescence histopathological analysis of IgG deposits and H\&E analysis of lupus-like alterations. (C) Expression of PD-1 and CXCR5 in $\mathrm{CD}^{+}$splenocytes. (D,E) Level of anti-dsDNA Abs in Balb/c and MRL/mpj mice detected by ELISA. All flow cytometry figures represent one set of experiments, and each experiment was repeated 10 times on different mice. The horizontal bars represent the mean \pm SEM.

TET2 was positively correlated with the percentage of CXCR5 ${ }^{+} \mathrm{PD}-1^{+}$cells during Tfh cell differentiation, suggesting that TET2 plays a role in Tfh cell differentiation. The role of TET 2 was confirmed by using TET2 siRNA to knock down TET2 expression during Tfh cell differentiation. TET2 siRNA dramatically decreased the percentage of Tfh cells (CXCR5 ${ }^{+} \mathrm{PD}-1^{++}$) on Day 7 (Fig. 5D). The addition of $\mathrm{NaCl}$ slightly increased the percentage of CXCR $5^{+}$PD $-1^{++}$cells $(p=0.07)$, but had no effect on PD-1 mRNA level (Fig. 5E), indicating that TET2 played an important role in Tfh cell differentiation and that $\mathrm{NaCl}$ promoted Tfh cell differentiation in a TET2-dependent manner. The increased number of $\mathrm{CXCR}^{+} \mathrm{PD}-1^{++}$cells induced by $\mathrm{NaCl}$ may be a result of slightly increased TET2 protein levels (Fig. 5F) after siRNA transfection.

$\mathrm{NaCl}$ enhances the expression of map3k1 and spn and induces DNA hypomethylation of genes that are involved in the immune response pathway. To further explore the mechanism of $\mathrm{NaCl}$-induced Tfh cell promotion, a gene expression map and DNA methylation map were constructed for 
A

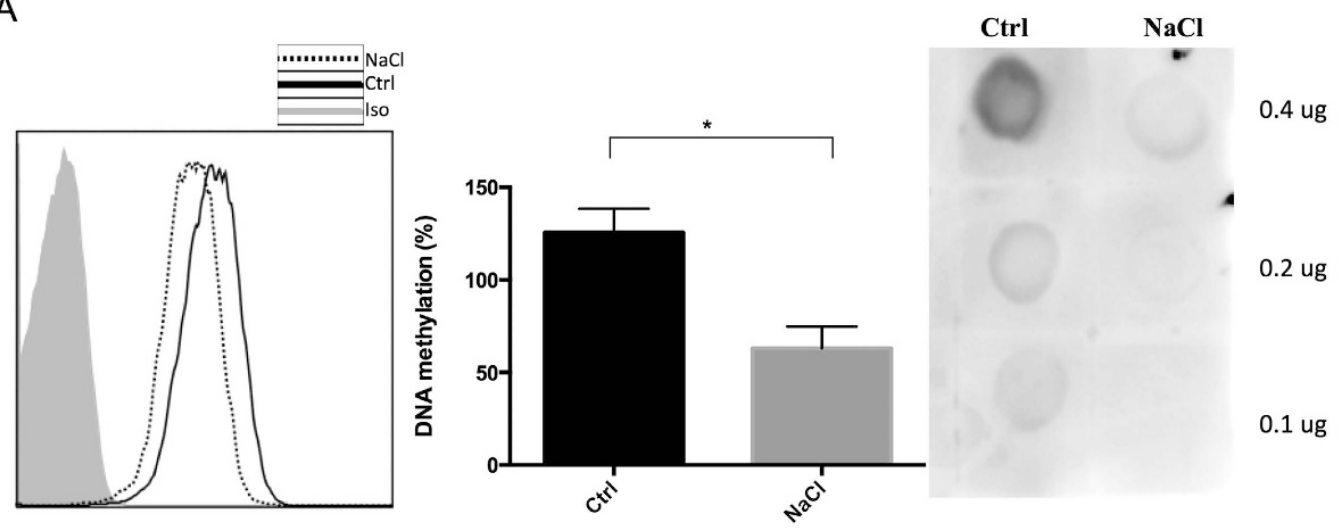

B
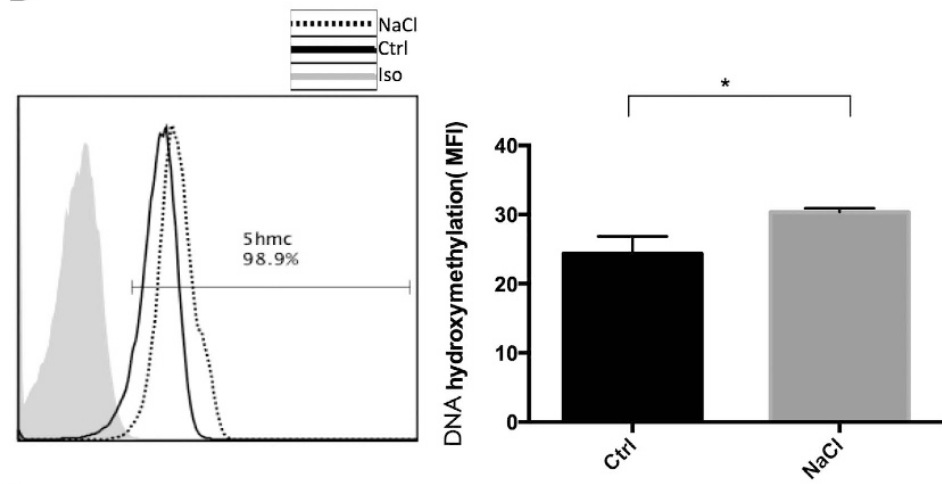

$\mathrm{Ctrl} \mathrm{NaCl}$

C
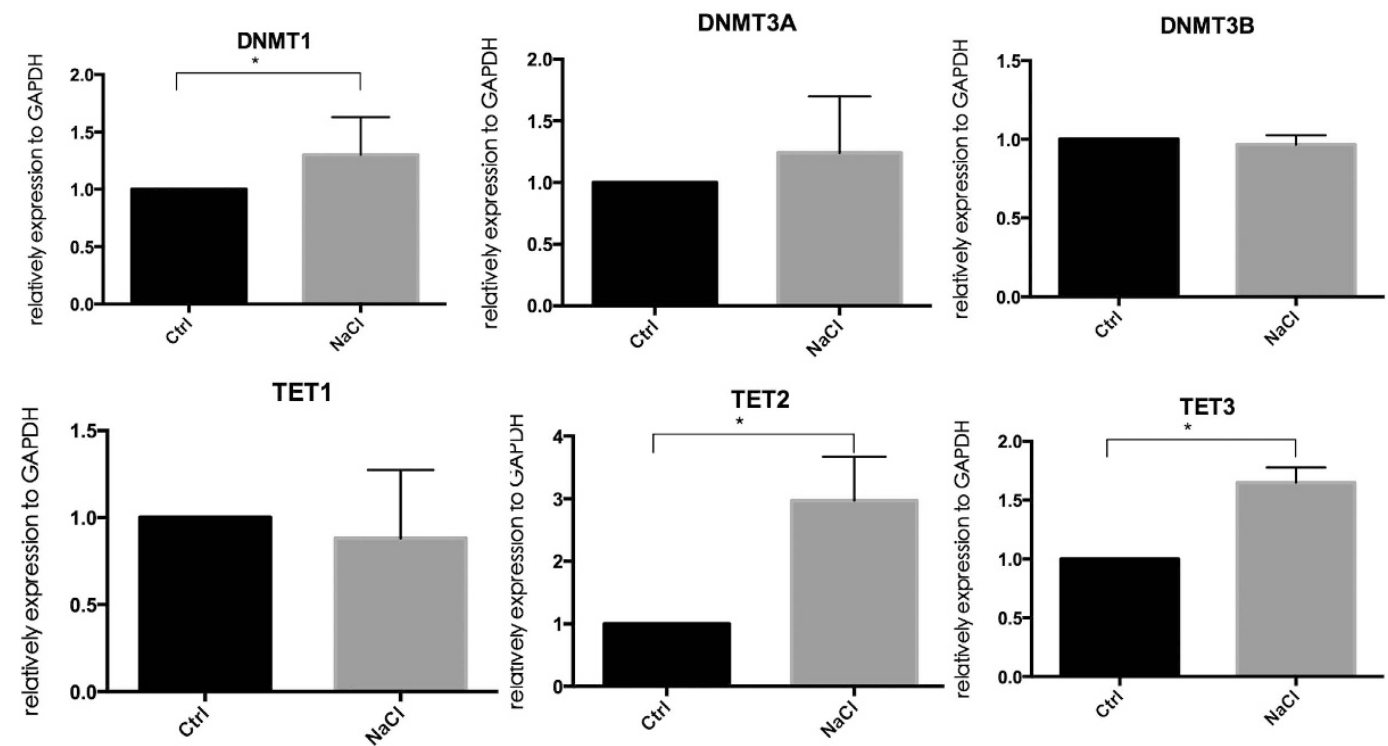

Figure 4. $\mathrm{NaCl}$ induces DNA hypomethylation on $\mathrm{CD}^{+} \mathrm{T}$ cells and enhances the gene expression of TET2 and TET3. Normal human CD4 ${ }^{+} \mathrm{T}$ cells were isolated and cultured with or without $\mathrm{NaCl}$ for $48 \mathrm{hr}$. (A) DNA methylation levels were measured by flow cytometry and DNA dot plot $(n=6)$. (B) DNA hydroxymethylation levels were measured by flow cytometry and DNA dot plot $(n=6)$. (C) Gene expression of DNMT1, DNMT3A, DNMT3B, TET1, TET2 and TET3 relative to GAPDH was measured by qPCR and normalized to the control $(\mathrm{n}=10)$. All flow cytometry figures and dot plot figures represent one set of experiments, and each experiment was repeated at least six times on different individuals. The horizontal bars represent the mean \pm SEM. $* p<0.05$.

control and $\mathrm{NaCl}$-treated human $\mathrm{CD} 4^{+} \mathrm{T}$ cells. Compared with control cells, the high-salt-treated cells exhibited decreased gene expression of Blimp, IL-4, IL-10, IFN- $\gamma$, and IL-2 (2-fold change, $p<0.05)$ and enhancement of T helper cell subset differentiation genes, such as ICOS, PDCD1, STAT1, and Sh2d1a, and other genes involved in $\mathrm{T}$ cell differentiation and activation ( 2 -fold change, $p<0.05$, Fig. 6A). However, transcription factors that are 
A

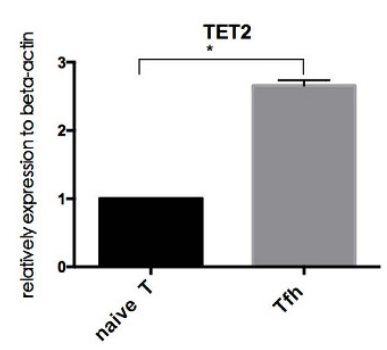

D

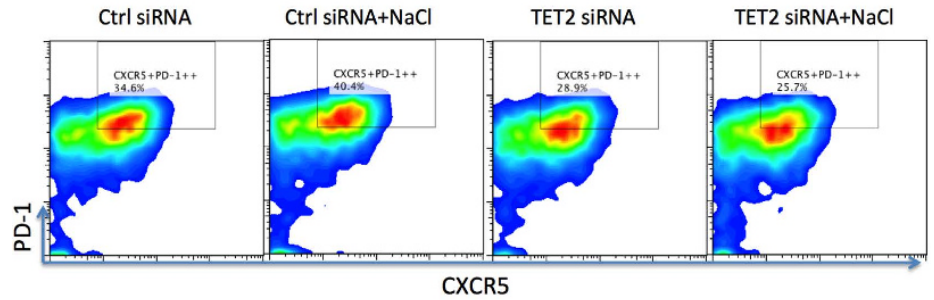

E

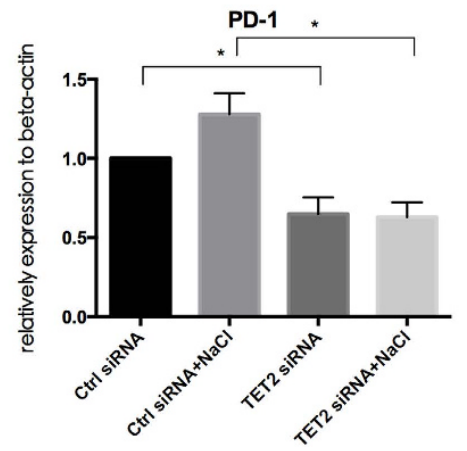

B

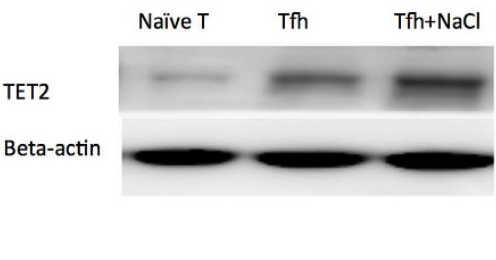

$\mathrm{F}$

TET2

actin
C

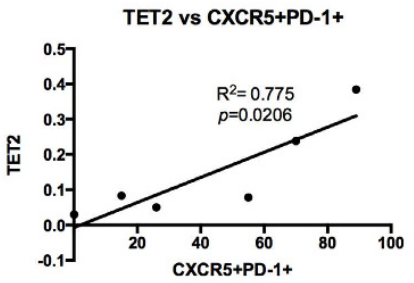

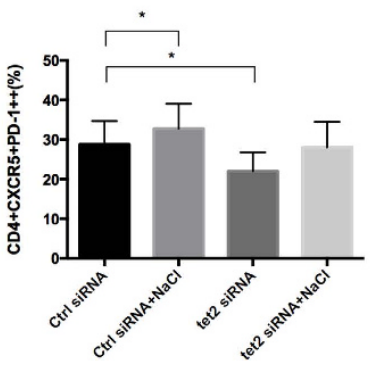

\section{Ctrl $\mathrm{Ctrl}+\mathrm{NaCl}$ TET2 TET2+NaCl}

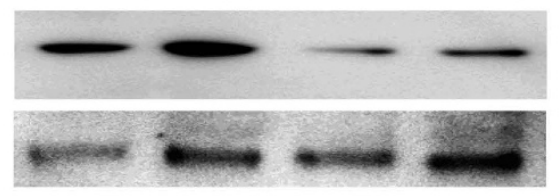

Figure 5. TET 2 plays an important role in $\mathrm{Tfh}$ cell differentiation and $\mathrm{NaCl}$-induced $\mathrm{Tfh}$ cell promotion. (A) TET2 gene expression during Tfh cell differentiation (Day 7, $\mathrm{n}=6$ ). (B) Protein level of TET2 as determined by western blot during Tfh cell differentiation and after $\mathrm{NaCl}$ treatment (Day 7, $\mathrm{n}=3$ ). (C) The correlation of TET2 and CXCR5 ${ }^{+} \mathrm{PD}-1^{+}$cells during Th cell differentiation (Day0, 1, 3, 5, 6, 7, $\mathrm{n}=3$ ). (D) Normal naïve T cells were transfected with TET2 siRNA or control siRNA and then differentiated into Tfh cells in the presence or absence of $\mathrm{NaCl}$. The percentage of activated Tfh cells $\left(\mathrm{CD} 4{ }^{+} \mathrm{PD}-1^{++} \mathrm{CXCR} 5^{+}\right)$was detected by flow cytometry $(\mathrm{n}=4)$. Statistical analysis of the Th cell percentage as determined by flow cytometry. (E) The mRNA level of PD-1 ( $n=3)$. (F) The protein level of TET2 in Tfh cells after transfection $(n=3)$. All flow cytometry figures and western blot figures represent one set of experiments, and each experiment was repeated at least three times on different individuals. The horizontal bars represent the mean \pm SEM. $* p<0.05$.

essential for T helper cell differentiation, such as BCL-6, TBX21, GATA3, FOXP3 and ROR $\gamma$ t, did not exhibit significant changes. However, BCL- 6 showed significant changes in 10 normal CD4 ${ }^{+} \mathrm{T}$ cells by the high-salt treatment, which was detected by QPCR (Fig. 6D).

Among the genes involved in $\mathrm{T}$ cell differentiation and activation that were increased by $\mathrm{NaCl}$ by more than 2 -fold, sh2d1a, map3k1, spn and stat5b attracted our attention and were validated in 10 normal CD $4^{+} \mathrm{T}$ cells (Fig. 6B). In addition, $\mathrm{NaCl}$ treatment increased the expression of CD40L at the protein (Fig. 1C) and mRNA levels in $\mathrm{CD}^{+} \mathrm{T}$ cells, but these increases did not differ significantly from the gene expression map (Fig. 6B). Furthermore, blimp, which promotes Th17, Th1 and Th2 and represses Tfh cell differentiation ${ }^{25}$, was also validated in $10 \mathrm{NaCl}$-treated $\mathrm{CD} 4^{+} \mathrm{T}$ cells.

Accordingly, the mRNA levels of sh2d1a, map3k1, spn and stat $5 \mathrm{~b}$ were measured in NC vs SLE CD4 ${ }^{+} \mathrm{T}$ cells and naïve vs Tfh cells (with or without $\mathrm{NaCl}$ ). As shown in Fig. $6 \mathrm{C}$, the gene expression of sh2d1a, map3 $\mathrm{k} 1$, spn and stat5b was significantly increased in SLE patients compared with NC subjects. However, no correlation was observed between the expression of these genes and the SLEDAI (data not shown). During Tfh differentiation, the expression of spn and stat5b was enhanced, and the addition of $\mathrm{NaCl}$ further increased these levels (Fig. 6D), indicating that these genes might be involved in Tfh differentiation and respond to $\mathrm{NaCl}$ treatment. The data from the methylation map revealed that $\mathrm{NaCl}$ induced $\mathrm{DNA}$ hypomethylation of genes (Fig. $6 \mathrm{E}$, $\mathrm{GO}$ analysis beta dif $<-0.02, \mathrm{p}<0.05)$ mainly involving cell differentiation, cellular development process, and immune system process. These data suggest that $\mathrm{NaCl}$ may activate cell differentiation and the immune system by inducing DNA hypomethylation. 
A
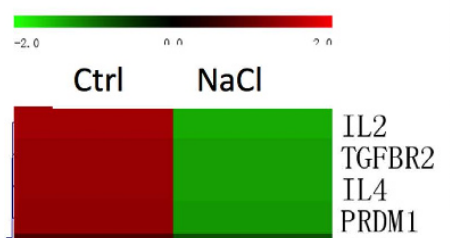

PRDM1

IL10

STAT1

JAK2

IFNG

FOXP3

NKX2-3

TGFB2

MET

SPN

SH2D1A

NCK1

ERBB2

STAT5B

PRDM11

SLC11A1

ZEB2

SHC1

IL17RC

HGF

ZAK

TGFA

TGFA

XRCC4

INSR

ITGAM

PRDX2

PRDX2

CXCR3

MAP3K 1

MINK1

PDCD1

BCL6

IL21R

CD40LG

CXCR5

BATF

GATA3

ICOS

IL6R

TBX21

IRF4

FOXP1

RORC
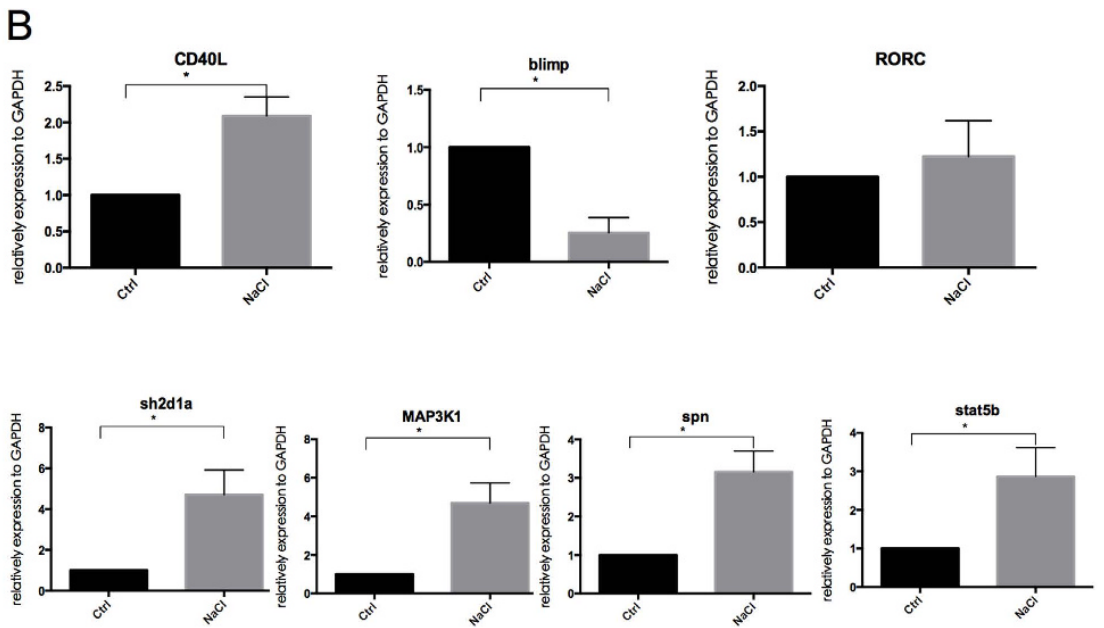

C
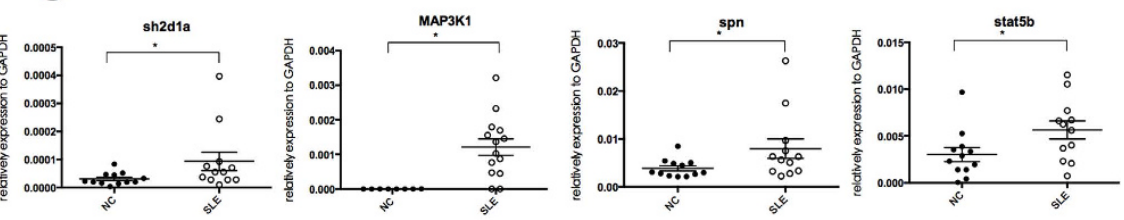

D
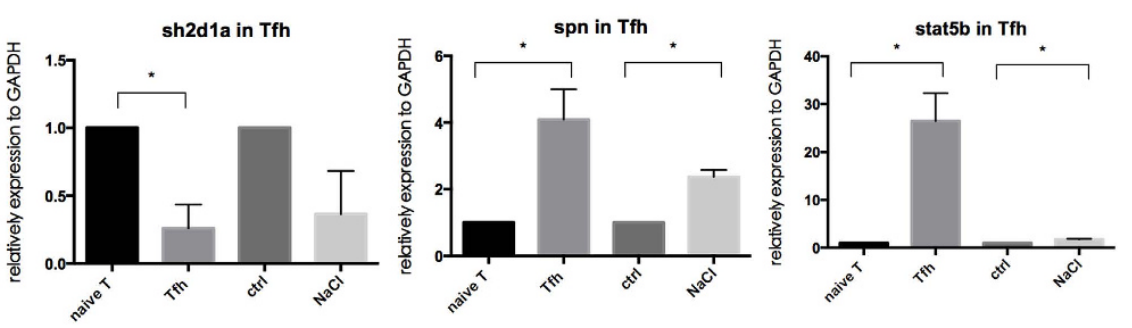

$E$

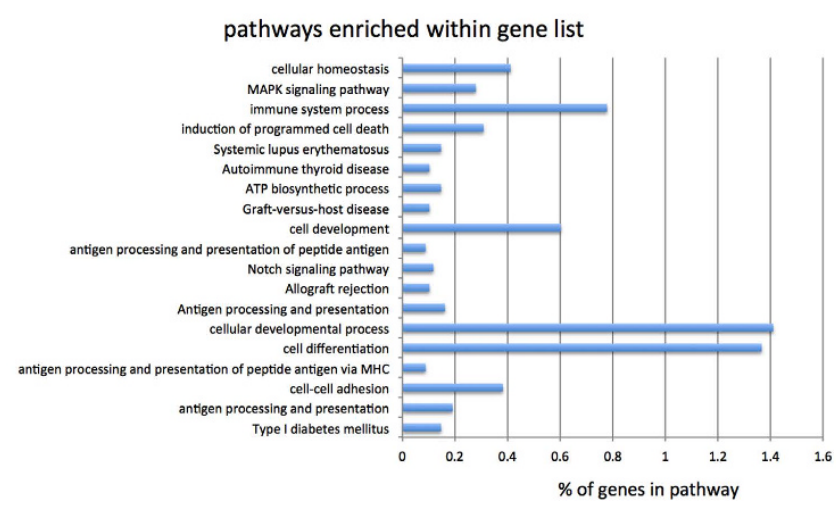

Figure 6. $\mathrm{NaCl}$ enhances the expression of map3k1 and spn and induces DNA hypomethylation of genes that are involved in the immune response pathway. (A) Heat map: These genes were selected based on their functions in Thelper cell subsets (more than 2 -fold change, $p<0.05$ ). (B) Gene expression on normal CD $4^{+} \mathrm{T}$ cells (with and without $\mathrm{NaCl}$ treatment for $48 \mathrm{hr}, \mathrm{n}=10$ ). (C) Gene expression on $\mathrm{CD}^{+} \mathrm{T}$ cells from normal controls $(\mathrm{n}=12)$ and SLE patients $(\mathrm{n}=12)$. (D) Gene expression during normal Tfh cell differentiation $(\mathrm{n}=3)$. (E) Methylation map: GO analysis beta dif $<-0.02, \mathrm{p}<0.05$. All flow cytometry figures and dot plot figures represent one set of experiments, and each experiment was repeated at least three times for different individuals. The horizontal bars represent the mean \pm SEM. $* p<0.05$.

$\mathrm{NaCl}$ treatment enriches TET2 on spn and stat5b, and TET2 silencing inhibits spn expression.

To further explore the interaction between TET2 and NaCl-increased genes (sh2d1a, map3k1, spn, stat5b, BCL6), ChIP-qPCR was performed. As shown in Fig. 7A, TET2 enrichment was observed on spn and stat5b $(n=6$, 
A
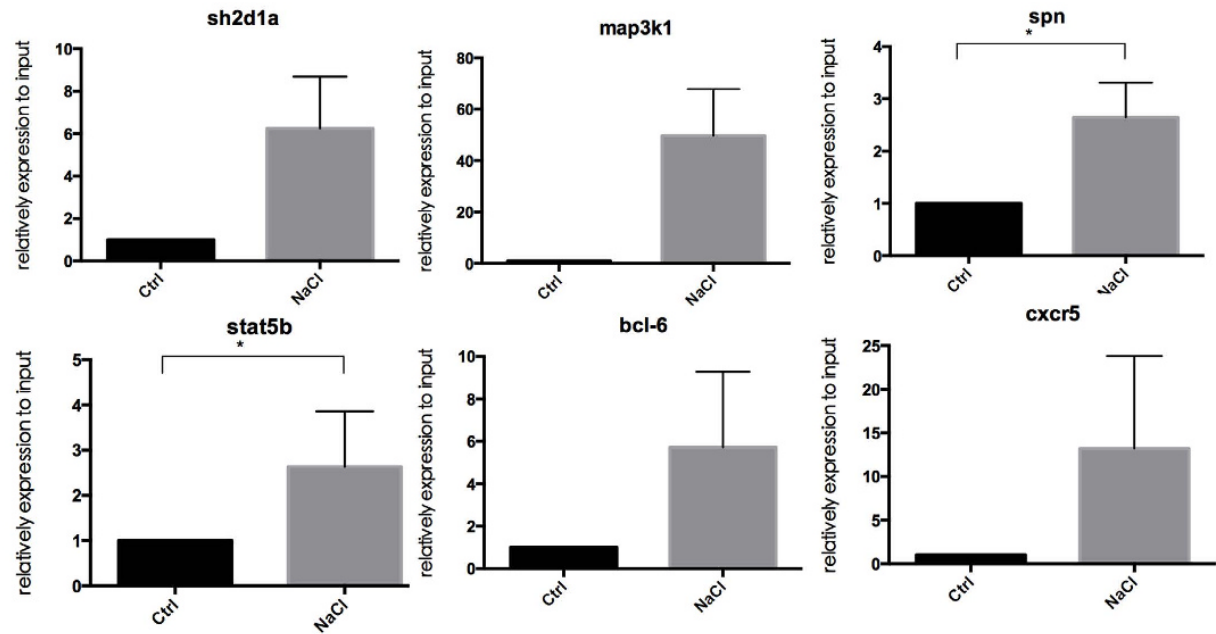

B
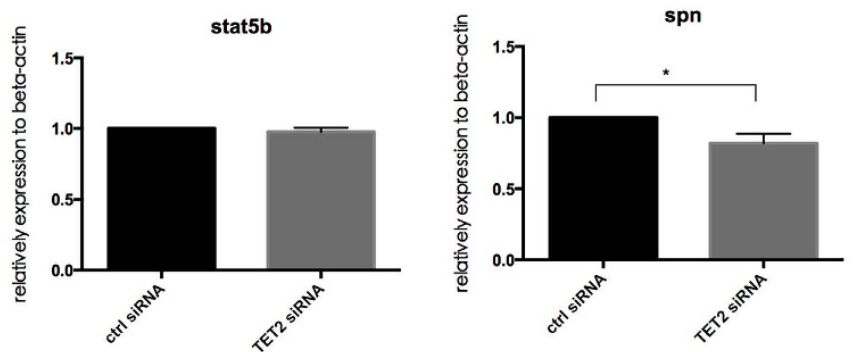

C
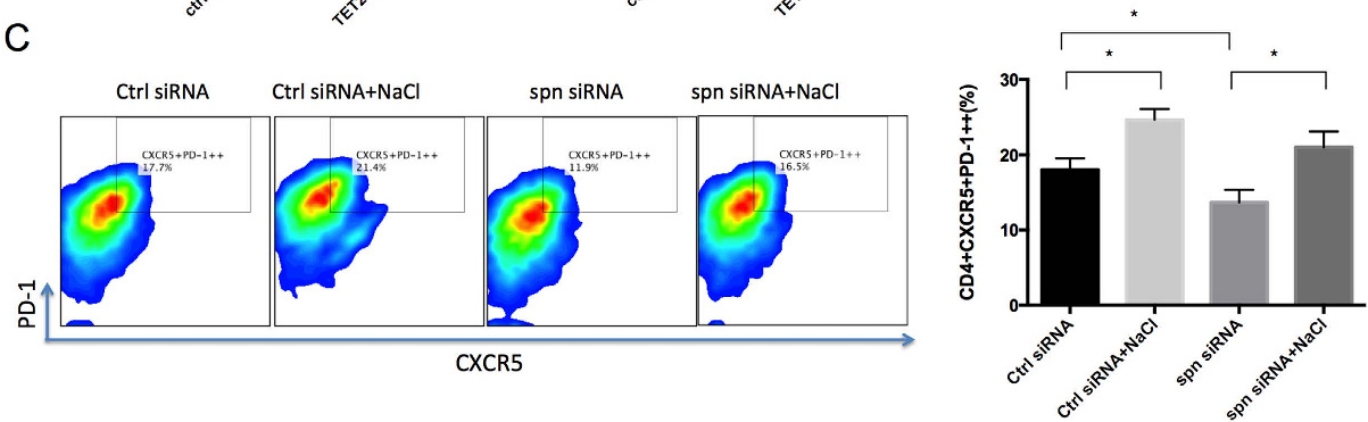

Figure 7. Enrichment of TET2 on spn and stat $5 \mathrm{~b}$ after $\mathrm{NaCl}$ treatment and TET2 regulation of spn expression. (A) Normal human $\mathrm{CD} 4{ }^{+} \mathrm{T}$ cells were isolated and cultured with or without $\mathrm{NaCl}$ for $48 \mathrm{hr}$. Then, the cell lysates were immunoprecipitated with $2 \mathrm{ml}$ of anti-TET2 antibody. DNA was eluted, and qPCR of sh2d1a, map3k1, spn, CXCR5, BCL-6 and stat5b was performed $(\mathrm{n}=6)$. (B) TET2 siRNA was applied to knock down TET2 during Tfh differentiation in the presence or absence of $\mathrm{NaCl}$. The mRNA levels of spn and stat $5 \mathrm{~b}$ were evaluated on Day $5(\mathrm{n}=3)$. (C) Normal human $\mathrm{CD} 4^{+} \mathrm{T}$ cells were isolated, transfected with spn siRNA and cultured with or without $\mathrm{NaCl}$ under Tfh cell differentiation conditions. The percentage of $\mathrm{CD} 4^{+} \mathrm{CXCR}^{+} \mathrm{PD}-1^{++}$Tfh cells was detected by flow cytometry $(\mathrm{n}=3)$. The horizontal bars represent the mean \pm SEM. $* p<0.05$.

$p<0.05$ ), indicating that increased expression of spn and stat $5 \mathrm{~b}$ might be associated with the enrichment of TET2 after $\mathrm{NaCl}$ addition. Then, the expression of these genes was evaluated after TET2 silencing. Moreover, TET2 silencing only affected spn expression statistically (Fig. 7B). To further silence spn during Tfh differentiation, spn siRNA reduced the CXCR5 ${ }^{+} \mathrm{PD}-1^{++}$cells, however, the addition of $\mathrm{NaCl}$ dampened its inhibiting effects (Fig. 7C), suggesting that spn regulated Tfh cell differentiation and served as one but not the only target for $\mathrm{NaCl}$.

\section{Discussion}

Accumulating evidence supports a role of high salt in immune disorders, including $\mathrm{EAE}^{6,26}$ and xenogeneic graft-versus-host disease (GVHD) model ${ }^{8}$. Pathogenic Th17 cells, which are important for development of EAE, are promoted by activation of the $\mathrm{p} 38 / \mathrm{MAPK}$ pathway by $\mathrm{NaCl}^{6}$. High salt attenuates the function of regulatory T cells (Tregs) and induces IFN- $\gamma$-producing Tregs mediated by serum/glucocorticoid-regulated kinase (SGK1) ${ }^{8}$, thus aggravating GVHD. Specific activation is observed on macrophages induced by $\mathrm{NaCl}$-triggered activation of $\mathrm{p} 38 / \mathrm{cFos}$ and/or Erk $1 / 2 / \mathrm{cFos}$ pathways $\mathrm{s}^{27}$, as well as NF-kB and MAPK signaling pathways ${ }^{26}$, promoting lung inflammation and central nervous system autoimmunity, respectively. These findings indicate that high salt promotes autoimmunity via pro-inflammatory responses. 
In this study, we observed an enhanced frequency of Tfh cells rather than Th $17^{6}$ and Treg cells ${ }^{8}$. These might due to the different cell population (PBMCs and CD4 $4^{+} \mathrm{T}$ cells) we investigated. In Th17 cell investigation, purified $\mathrm{CD} 4^{+}$naïve $\mathrm{T}$ cells were the target cells. Unlike the mixture of PBMCs and CD4 ${ }^{+} \mathrm{T}$ cells, the differentiation of Th cells would not be affected by other cells, such as antigen presenting cells and memory T cells. However, in physiological condition, cells in lymphoid organs are more like a mixture of cells rather than purified naïve $\mathrm{T}$ cells. As shown in Fig. 1, NaCl significantly increased the percentage of $\mathrm{CD} 4{ }^{+} \mathrm{CXCR} 5^{+} \mathrm{PD}-1^{+}$cells and the size of the $\mathrm{ICOS}^{+}$population, indicating that $\mathrm{NaCl}$ enhanced the number and function of Tfh cells. The role of Tfh cells in SLE has been well documented. In the Roquin ${ }^{\text {san/san }}$ mouse model, the pathogenic roles of Tfh have been clearly demonstrated to involve impaired function of the post transcriptional repressor Roquin, which causes the development of a lupus-like syndrome. This process is mediated by excessive Tfh cell and GC responses ${ }^{28-30}$, and Tfh cells also contribute to lupus in MRL/lpr mice ${ }^{31,32}$. Additionally, multiple lines of evidence indicate a pathogenic role of Tfh cells in human lupus, such as alterations in the phenotype of circulating Tfh (cTfh) cells ${ }^{32323123}$ and increases in their numbers ${ }^{20-22}$. The differential expression of ICOS and PD-1 on human cTfh cell subsets further defines distinct subpopulations: an activated subset $\left(\mathrm{ICOS}^{+} \mathrm{PD}-1^{++}\right)$and two quiescent subsets (ICOS-PD- $1^{+}$and ICOS PD $\left.-1^{-}\right)^{33}$. In SLE, the activated subset $\left(\mathrm{ICOS}^{+}\right.$or PD-1 ${ }^{++}$) of cTfh cells is increased and is positively correlated with serum autoantibody titers and disease activity and/or severity ${ }^{25}$. We previously observed a significant increase in the PD $-1^{++} \mathrm{CXCR}^{+}$population in SLE (unpublished data) as well as an increase in PD-1 ${ }^{++}$Tfh cells after $\mathrm{NaCl}$ treatment (Fig. 1), indicating activation of the Tfh subset in SLE and high-salt conditions. In addition, $\mathrm{MRL} / \mathrm{lpr}$ mice that received a high-salt diet exhibited accelerated disease progression, with a higher proportion of Tfh cells in the spleen (Fig. 2). However, Balb/c and MRL/mpj mice failed to develop severe lupus-like symptom, even though IgG deposits and proteinuria were slightly elevated in the high-salt group (Fig. 3), suggesting that the risk of lupus is influenced by complex genetic and environmental contributions.

Epigenetic modulation is considered one of the mechanisms involved in $\mathrm{NaCl}$ promotion of Tfh cell differentiation, based on previous reports that Vitamin B, folate, methionine (Met), choline and $\mathrm{Zn}^{9}$ are required to maintain a normal level of DNMT $1^{10}$. We observed enhancement of DNMT1 in the high-salt group. However, global DNA methylation levels were dramatically attenuated by $\mathrm{NaCl}$ (Fig. 4), and the significant increase in TET2 levels might be a contributor. In addition, the high-throughput MDIP-seq data suggest that $\mathrm{NaCl}$ treatment mainly reduces DNA methylation levels of genes involved in T cell activation and differentiation (Fig. 5). TET2 proteins catalyze the conversion of 5-methylcytosine $(5 \mathrm{mC})$ to 5 -hydroxymethylcytosine $(5 \mathrm{hmC})$ to mediate DNA demethylation. Accumulating evidence indicates that TET2 controls the methylation and differentiation of Th1 and Th17 cells by recruitment on lineage-specific cytokine genes, such as Il6 and Infg ${ }^{34}$. Although TET2 is a negative regulator in Tfh cells in mice ${ }^{35}$, our in vitro results for human Tfh cells strongly support a positive role of TET2 in Tfh cell differentiation by promoting PD-1 and BCL-6 expression (Fig. 6). A direct interaction of TET2 and BCL- 6 was also observed by ChIP-seq (Fig. 7), suggesting a regulatory role of TET2 in Tfh cell differentiation. However, no difference in IL-21 expression and no TET2 enrichment on the Il21 gene were observed.

The data from high-throughput sequencing suggests that several genes involved in $\mathrm{T}$ cell differentiation and activation are activated by high-salt treatment, such as sh $2 \mathrm{~d} 1 \mathrm{a}, \mathrm{map} 3 \mathrm{k} 1$, spn and stat $5 \mathrm{~b}$. The expression of these four genes was also higher in lupus $\mathrm{CD}^{+} \mathrm{T}$ cells (Fig. 6). TET2 silencing revealed that only spn interacts with TET2 and is affected by TET2 silencing. Spn (CD43) is a transmembrane glycoprotein with an elongated extracellular domain and a highly conserved intracytoplasmic tail ${ }^{36}$. Numerous ligands of spn have been identified, such as ICAM-1, MHC-I, E-selectin, and galectin-1, and complex glycosylation patterns of spn have been observed in pathogens such as viruses, $M$. tuberculosis and T. cruzi, indicating that spn can act as a pathogen recognition receptor. The colligation of spn with the $\mathrm{T}$ cell receptor promotes $\mathrm{T}$ cell proliferation and IL-2 production by enhancing ERK activation ${ }^{37}$. We observed that spn played an essential role in T cell differentiation. Naïve T cells in which spn was knocked down by siRNA exhibited no response to CD3CD28 activation. Thus, silencing of spn was conducted in $\mathrm{CD}^{+} \mathrm{T}$ cells instead. After silencing, the Tfh cell population decreased, and $\mathrm{NaCl}$ reversed these effects (Fig. 7), suggesting that spn played a critical role in Tfh cell differentiation and $\mathrm{NaCl}$ might promote Tfh cells and not exclusively through spn.

In the present study, we identified a high-salt diet as an environmental factor that promotes SLE by inducing Tfh cell differentiation. However, in the mouse model, the effects of a high-salt diet were much more complicated than that in the in vitro system. This difference may be attributable to Tfh cells. Pathogenic Th17 cells, activated macrophages, and function-reduced Treg cells might work together to contribute to SLE progression, but Tfh cells play a significant role in modulating the epigenetic effects of the environment. In vivo effects of high-salt in lupus mice were not unlikely attributed to increased GFR due to a saline diuresis because the high-salt diet failed to have similar results in normal mice. Although the higher concentration of $\mathrm{NaCl}$ was observed in lymphoid tissues in mice, the hypertonicity might also contribute to the immune cells. But at least, our data indicate that lupus patients would be better to reduce salt in-take and the underlying mechanism might provide new therapeutic target for SLE, with interference TET2 and spn to attenuate pathogenic Tfh cells.

\section{Materials and Methods}

Subjects and mice. A total of 12 SLE patients who fulfilled at least 4 of the SLE classification criteria of the American College of Rheumatology were recruited from outpatient clinics in the Second Xiangya Hospital of Central South University ${ }^{38}$. Lupus disease activity was assessed using the SLE Disease Activity Index (SLEDAI) ${ }^{39}$. The characteristics of SLE patients are shown in S Table 1. A total of 54 healthy controls were recruited from the medical staff at the Second Xiangya Hospital and Changsha Blood Center. The information of healthy control is shown in S Table 1 and 2. Patients and controls were matched for age and sex in all experiments. The human sample study was approved by Ethics Committee of Second Xiangya Hospital, Central South University, and the 
methods were carried out in accordance with the approved guidelines. Written informed consent was obtained from all subjects.

MRL/lpr, MRL/mpj and Balb/c mice were purchased from Jackson Laboratory (USA). Twenty 12-week-old female MRL/lpr, MRL/mpj and Balb/c mice were randomized into 2 groups, either receiving normal chow and tap water ad libitum (control group) or sodium-rich chow containing $4 \% \mathrm{NaCl}$ and tap water containing $1 \% \mathrm{NaCl}$ ad libitum (high-salt group) every day. Mouse studies were approved by the Animal Care and Use Committee of Second Xiangya Hospital, Central South University, and the methods were carried out in accordance with the approved guidelines.

Cell isolation, culture and differentiation. PBMCs were separated from the peripheral blood of healthy controls and SLE patients by density gradient centrifugation (GE Healthcare, Switzerland). CD $4^{+} \mathrm{T}$ and B cells were isolated by positive selection using Miltenyi beads according to the manufacturer's instructions (Miltenyi, Germany). $\mathrm{CD}^{+} \mathrm{CDRA}^{+} / \mathrm{RO}^{-}$naïve $\mathrm{T}$ cells were isolated by negative selection by Miltenyi beads according to the manufacturer's instructions. The purity of the enriched subset was validated by flow cytometry and was generally higher than $95 \%$.

$\mathrm{NaCl}$ (Sigma, USA) $(16 \mathrm{mM}, 80 \mathrm{mM}$ and $160 \mathrm{mM})$ was added to PBMCs and CD4 ${ }^{+} \mathrm{T}$ cells $\left(5 \times 10^{5} \mathrm{cell} / \mathrm{ml}\right)$ for $48 \mathrm{hr}$. In some experiments, $\mathrm{NaCl}$ was added to PBMCs in the presence of anti-CD3 and anti-CD28 $(1 \mu \mathrm{g} /$ $\mathrm{ml}$, eBioscience, USA), and Golgi stop (BD Pharmingen, USA), PMA (50 ng/ml) and ionomycin (750 $\mathrm{ng} / \mathrm{ml}$, Sigma, USA) were added for last $4 \mathrm{hr}$ of culture. Cells and supernatants were harvested for subsequent analysis. Tfh cell differentiation: $\mathrm{CD}^{+} \mathrm{CDRA}^{+} / \mathrm{RO}^{-}$naïve $\mathrm{T}$ cells were seeded in anti-CD3 antibody $(1 \mu \mathrm{g} / \mathrm{ml})$ pre-coated 24 -well plates $\left(2.5 \times 10^{5} \mathrm{cell} / \mathrm{ml}\right)$ with or without $\mathrm{NaCl}$ in the presence of anti-CD28 antibody $(1 \mu \mathrm{g} / \mathrm{ml})$, IL-6 $(5 \mu \mathrm{g} / \mathrm{ml})$, TGF- $\beta(1 \mu \mathrm{g} / \mathrm{ml})$, IL-1 $\beta(10 \mu \mathrm{g} / \mathrm{ml})$ and IL-23 $(10 \mu \mathrm{g} / \mathrm{ml})$ for 7 days. The medium was refreshed on Day 3 and Day $5^{40}$. The cells were harvested for subsequent analysis.

Flow cytometry. To examine the expression of surface markers and intracellular molecules, cells were incubated with FcR blocking reagent (Miltenyi, Germany) for 10 min followed by primary antibodies on ice in the dark for $30 \mathrm{~min}$. The antibodies used for surface marker analysis included anti-human CD4-FITC, CXCR5-PE, PD-1-PE-cy7, BCL-6-APC, CD25-PE, CD19-FITC, CD138-PE (BD Pharmingen, USA), and anti-mouse CD4-FITC, CXCR5-APC, PD-1-PE, and CD138-PE (eBioscience, USA). For intracellular staining, cells were cytofixed and cytopermed using the CytofixCytoperm Plus kit (BD Pharmingen, USA) and stained with intracellular antibodies, including anti-human IL-17-APC, IFN- $\gamma$-PE, IL-4-PE-cy5, Foxp3-APC (BD Pharmingen, USA), 5-mC and 5-hmC (Abcam, USA) for an additional $30 \mathrm{~min}$ on ice in the dark. For some experiments, apoptosis was detected using a FITC Annexin V Apoptosis Detection Kit II (BD Pharmingen, USA). Data were acquired by flow cytometry (BD, Canto II, USA) and analyzed using FlowJo (Tree Star, USA).

Cytokine detection by Bio-plex. Supernatants were harvested from cultures and stored at $-80^{\circ} \mathrm{C}$ for subsequent cytokine measurement. Cytokines including IL-4, IL-6, IL-17A, IL-17F, IL-21, IL-23, IFN- $\gamma$ and IL-10 were measured by a Bio-Plex Pro human Th17 cytokine assay, and data were recorded on a Bio-plex 200 system (Bio Rad, USA).

DNA dot plot. DNA was extracted from $\mathrm{CD}^{+} \mathrm{T}$ cells by a QIAamp DNA Mini kit (QIAGEN, USA). The dot plot procedure was performed as described by Abcam. Briefly, a pencil was used to draw a grid on the nitrocellulose membrane (Bio-Rad, USA). A narrow-mouth pipette tip was used to spot $2 \mu$ l of DNA samples onto the nitrocellulose membrane at the center of the grid. The area the solution penetrated was minimized, and the membrane was allowed to dry. Non-specific sites were blocked by soaking in 5\% BSA (Sigma, USA) in TBS-T for $1 \mathrm{hr}$ at room temperature. The membrane was then incubated with $5-\mathrm{mC}$ and $5 \mathrm{hmC}$ primary antibody (Abcam, USA, 1:2000) dissolved in BSA/TBS-T for $30 \mathrm{~min}$ at room temperature. The membrane was washed three times with TBS-T and incubated with a HRP-conjugated secondary antibody (Abcam, USA, 1:4000) for $30 \mathrm{~min}$ at room temperature. The membrane was washed three times with TBS-T, incubated with ECL reagent for $1 \mathrm{~min}$, covered with plastic wrap, and exposed to X-ray film in the dark.

Quantitative PCR. Total RNA was extracted from cells using Trizol reagent (Invitrogen, USA). The sample was reverse-transcribed with the PrimeScript ${ }^{\circledR}$ RT reagent kit with gDNA Eraser (TaKaRa Biotech Co., China) using $1 \mu \mathrm{g}$ of total RNA according to the manufacturer's instructions. The reaction mixture contained $2 \mu \mathrm{l}$ of cDNA, $10 \mu \mathrm{l}$ of SYBR Premix Ex Taq ${ }^{\mathrm{TM}}$ (TaKaRa Biotech Co., China), and $400 \mathrm{nM}$ sense and antisense primers to a final volume of $20 \mu \mathrm{l}$. Transcripts were measured using a Rotor-Gene3000 (Corbett Research, NSW, Australia) thermocycler. The quantity of gene expression was calculated using the $2^{-\Delta \mathrm{Ct}}$ method and normalized to GAPDH. Primers for BCL-6, DNMT1, TET2, TET3, Blimp, CD40L, STAT5B, SPN, SH2D1A, and MAP3K1 were purchased from Life Technologies, USA.

Western blotting. Proteins in cell lysates were quantified by the Bradford assay (HyClone-Pierce, USA) followed by $12 \%$ vertical dodecyl sulfate-polyacrylamide gel electrophoresis and transferred to nitrocellulose membranes (Millipore, USA). The membrane was blocked in TBS/5\% skim milk and then incubated with mouse anti-human BCL-6 or TET2 monoclonal antibody (Santa Cruz, USA) for $1 \mathrm{~h}$, followed by HRP-rabbit anti-mouse IgG antibody (Santa Cruz, USA). Proteins were detected with an ECL Western blot detection kit (Thermo Scientific, USA). Quantification of BCL-6 or TET2 was normalized to $\beta$-actin by densitometry.

Chromatin immunoprecipitation (ChIP)-qPCR. To explore the possible molecular mechanisms of $\mathrm{NaCl}$ in regulating immune cells, we analyzed the binding of TET2 at $\operatorname{sh} 2 d 1 a$, stat $5 b$, map $3 k 1$ and $s p n$. Chromatin 
immunoprecipitation (ChIP) assays were performed with a ChIP kit (Millipore, USA). According to the protocol, $\mathrm{CD} 4^{+} \mathrm{T}$ cells, with or without $\mathrm{NaCl}$ treatment, were fixed in $1 \%$ formaldehyde and then lysed for $10 \mathrm{~min}$ on ice. Chromatin was sheared by sonication. After preclearing with protein-G agarose beads, the cell lysates were immunoprecipitated overnight at $4^{\circ} \mathrm{C}$ with $2 \mathrm{ml}$ of anti-TET2 antibody (Millipore, USA). Then, protein G agarose beads were added and the resulting mixture was rotated for $1 \mathrm{hr}$ at $4^{\circ} \mathrm{C}$. After washing and elution, cross-links were reversed by heating at $65^{\circ} \mathrm{C}$ for $4 \mathrm{~h}$. The eluted DNA was purified, and the samples were analyzed by qPCR with input DNA (total chromatin) as an endogenous control. SYBR Premix Ex Taq ${ }^{\mathrm{TM}}$ was used to detect the enrichment of $\operatorname{sh} 2 d 1 a$, stat $5 b, m a p 3 k 1$ and $s p n$ (primers were purchased from life technology, USA).

siRNA silencing. Transfection was performed using Human T Cell Nucleofector kits and nucleofector (Amaxa, Germany). Control-siRNA, TET2-siRNA, and spn-siRNA were purchased from Life technology, USA. T cells transfected with control-siRNA or siRNA were treated with or without $80 \mathrm{mM} \mathrm{NaCl}$ for $48 \mathrm{hr}$. The cells and supernatants were harvested for subsequent analysis.

High throughput sequencing and MDIP-seq. $\mathrm{NaCl}$ (Sigma, USA) was added to CD $4^{+} \mathrm{T}$ cells $\left(5 \times 10^{5}\right.$ cell $/ \mathrm{ml}$ ) for $48 \mathrm{hr}$. DNA and RNA was extracted and high throughput sequencing and MDIP-seq were conducted by Shanghai Biotechnology Corporation, China.

Animal experiments. Proteinuria. Proteinuria was semi-quantitatively assessed biweekly using Albustix assay strips (Siemens Healthcare Diagnostics). The levels of urinary albumin were scored as follows: $0=$ trace; $1=30-99 \mathrm{mg} / \mathrm{d} ; 2=100-299 \mathrm{mg} / \mathrm{dl} ; 3=300-1999 \mathrm{mg} / \mathrm{dl}$; and $4=>2000 \mathrm{mg} / \mathrm{dl}$.

Anti-dsDNA antibody detection by ELISA: Mouse blood samples were collected from the lateral saphenous vein biweekly. A 100- $\mu \mathrm{l}$ volume of blood was collected in pre-calibrated micro-hematocrit tubes with heparin and then centrifuged at $13000 \mathrm{rpm}$ for 10 minutes. Plasma was collected, aliquoted and stored for further use. Anti-dsDNA antibody levels were detected by mouse anti-dsDNA IgG, IgG1, IgG2a, and IgM ELISA Kit (Alpha Diagnostic Intl, USA). The OD value was recorded by enzyme-labeled instrument, Enspire, USA.

Histopathology. Mice were sacrificed at 28 -week-age, and kidneys were collected, fixed in $10 \%$ buffered formalin, and embedded in paraffin. Hematoxylin and eosin (H\&E), Masson and pasm staining were performed. Glomerular injury was observed under a microscope (Leica, Germany).

Immunofluorescence histopathology. Kidneys were snap-frozen in liquid nitrogen and embedded in Optimal Cutting Temperature compound (Leica, Germany). After blocking with 1\% BSA, frozen sections ( $3 \mu \mathrm{m}$ thick) were stained with Alexa 488-conjugated anti-mouse IgG (1:100, Biolegend, USA) or rabbit anti-mouse C3 antibody (1:100, BD Pharmingen, USA) in a dark, humidified chamber for $1 \mathrm{hr}$ and washed with PBS. For C3 detection, sections were incubated with a DyLight 594-conjugated goat anti-rabbit secondary antibody (1:500, Genecopoeia, USA) for $1 \mathrm{hr}$, washed with PBS, mounted and visualized by fluorescence microscopy.

Statistical analysis. All diagrams and graphs report cumulative data as means \pm standard error of the mean (SEM). Distributions of means were analyzed with non-parametric tests (SPSS 16.0, USA). Differences within individual treatments were analyzed by paired t-test. A $p$-value $<0.05$ was considered statistically significant.

Study approval. Patients and controls were matched for age and sex in all experiments. Written informed consent was obtained from all subjects. Mouse studies were approved by the Animal Care and Use Committee of Second Xiangya Hospital, Central South University.

\section{References}

1. D'Cruz, D. P., Khamashta, M. A. \& Hughes, G. R. Systemic lupus erythematosus. Lancet 369, 587-596, doi: 10.1016/S01406736(07)60279-7 (2007).

2. Danchenko, N., Satia, J. A. \& Anthony, M. S. Epidemiology of systemic lupus erythematosus: a comparison of worldwide disease burden. Lupus 15, 308-318 (2006).

3. Takeno, M. et al. Autoreactive T cell clones from patients with systemic lupus erythematosus support polyclonal autoantibody production. Journal of immunology 158, 3529-3538 (1997).

4. Santulli-Marotto, S., Retter, M. W., Gee, R., Mamula, M. J. \& Clarke, S. H. Autoreactive B cell regulation: peripheral induction of developmental arrest by lupus-associated autoantigens. Immunity 8, 209-219 (1998).

5. Gatto, M. et al. Emerging and critical issues in the pathogenesis of lupus. Autoimmunity reviews 12, 523-536, doi: 10.1016/j. autrev.2012.09.003 (2013).

6. Kleinewietfeld, M. et al. Sodium chloride drives autoimmune disease by the induction of pathogenic TH17 cells. Nature 496 , 518-522, doi: 10.1038/nature11868 (2013).

7. Machnik, A. et al. Macrophages regulate salt-dependent volume and blood pressure by a vascular endothelial growth factor-Cdependent buffering mechanism. Nature medicine 15, 545-552, doi: 10.1038/nm.1960 (2009).

8. Hernandez, A. L. et al. Sodium chloride inhibits the suppressive function of FOXP3+ regulatory T cells. The Journal of clinical investigation 125, 4212-4222, doi: 10.1172/JCI81151 (2015).

9. Ross, S. A. \& Poirier, L. Proceedings of the Trans-HHS Workshop: diet, DNA methylation processes and health. The Journal of nutrition 132, 2329S-2332S (2002).

10. Somers, E. C. \& Richardson, B. C. Environmental exposures, epigenetic changes and the risk of lupus. Lupus 23, 568-576, doi: $10.1177 / 0961203313499419(2014)$.

11. Zhao, M. et al. DNA methylation and mRNA and microRNA expression of SLE CD4+ T cells correlate with disease phenotype. Journal of autoimmunity 54, 127-136, doi: 10.1016/j.jaut.2014.07.002 (2014).

12. Lu, Q. et al. Demethylation of ITGAL (CD11a) regulatory sequences in systemic lupus erythematosus. Arthritis and rheumatism 46, 1282-1291, doi: 10.1002/art.10234 (2002).

13. Zhao, M. et al. Epigenetics and SLE: RFX1 downregulation causes CD11a and CD70 overexpression by altering epigenetic modifications in lupus CD4+ T cells. Journal of autoimmunity 35, 58-69, doi: 10.1016/j.jaut.2010.02.002 (2010). 
14. Wu, H., Zhao, M., Chang, C. \& Lu, Q. The Real Culprit in Systemic Lupus Erythematosus: Abnormal Epigenetic Regulation. International journal of molecular sciences 16, 11013-11033, doi: 10.3390/ijms160511013 (2015).

15. Ma, C. S., Deenick, E. K., Batten, M. \& Tangye, S. G. The origins, function, and regulation of T follicular helper cells. The Journal of experimental medicine 209, 1241-1253, doi: 10.1084/jem.20120994 (2012).

16. Crotty, S. T follicular helper cell differentiation, function, and roles in disease. Immunity 41, 529-542, doi: 10.1016/j. immuni.2014.10.004 (2014)

17. Ueno, H., Banchereau, J. \& Vinuesa, C. G. Pathophysiology of T follicular helper cells in humans and mice. Nature immunology 16, 142-152, doi: $10.1038 /$ ni.3054 (2015).

18. Ansel, K. M., McHeyzer-Williams, L. J., Ngo, V. N., McHeyzer-Williams, M. G. \& Cyster, J. G. In vivo-activated CD4 T cells upregulate CXC chemokine receptor 5 and reprogram their response to lymphoid chemokines. The Journal of experimental medicine 190, 1123-1134 (1999).

19. Amaravadi, L. \& Klemsz, M. J. DNA methylation and chromatin structure regulate PU.1 expression. DNA and cell biology 18, 875-884, doi: 10.1089/104454999314737 (1999).

20. Wang, L. et al. Increased interleukin 21 and follicular helper T-like cells and reduced interleukin $10+B$ cells in patients with newonset systemic lupus erythematosus. The Journal of rheumatology 41, 1781-1792, doi: 10.3899/jrheum.131025 (2014).

21. Choi, J. Y. et al. Circulating follicular helper-like T cells in systemic lupus erythematosus: association with disease activity. Arthritis \& rheumatology 67, 988-999, doi: 10.1002/art.39020 (2015).

22. Zhang, X. et al. Circulating CXCR5+CD4+helper T cells in systemic lupus erythematosus patients share phenotypic properties with germinal center follicular helper T cells and promote antibody production. Lupus 24, 909-917, doi: 10.1177/0961203314567750 (2015).

23. Go, W. Y., Liu, X., Roti, M. A., Liu, F. \& Ho, S. N. NFAT5/TonEBP mutant mice define osmotic stress as a critical feature of the lymphoid microenvironment. Proceedings of the National Academy of Sciences of the United States of America 101, 10673-10678, doi: 10.1073/pnas.0403139101 (2004).

24. Oestreich, K. J., Mohn, S. E. \& Weinmann, A. S. Molecular mechanisms that control the expression and activity of Bcl-6 in TH1 cells to regulate flexibility with a TFH-like gene profile. Nature immunology 13, 405-411, doi: 10.1038/ni.2242 (2012).

25. Johnston, R. J. et al. Bcl6 and Blimp-1 are reciprocal and antagonistic regulators of T follicular helper cell differentiation. Science 325, 1006-1010, doi: 10.1126/science.1175870 (2009).

26. Hucke, S. et al. Sodium chloride promotes pro-inflammatory macrophage polarization thereby aggravating CNS autoimmunity. Journal of autoimmunity 67, 90-101, doi: 10.1016/j.jaut.2015.11.001 (2016).

27. Zhang, W. C. et al. High salt primes a specific activation state of macrophages, M(Na). Cell research 25, 893-910, doi: 10.1038/ cr.2015.87 (2015)

28. Vinuesa, C. G. et al. A RING-type ubiquitin ligase family member required to repress follicular helper T cells and autoimmunity. Nature 435, 452-458, doi: 10.1038/nature03555 (2005).

29. Pratama, A. et al. Roquin-2 shares functions with its paralog Roquin-1 in the repression of mRNAs controlling T follicular helper cells and systemic inflammation. Immunity 38, 669-680, doi: 10.1016/j.immuni.2013.01.011 (2013).

30. Vogel, K. U. et al. Roquin paralogs 1 and 2 redundantly repress the Icos and Ox40 costimulator mRNAs and control follicular helper T cell differentiation. Immunity 38, 655-668, doi: 10.1016/j.immuni.2012.12.004 (2013).

31. Agarwal, S. \& Rao, A. Modulation of chromatin structure regulates cytokine gene expression during T cell differentiation. Immunity 9, 765-775 (1998).

32. Yang, X. et al. T follicular helper cells mediate expansion of regulatory B cells via IL-21 in Lupus-prone MRL/lpr mice. PloS one 8, e62855, doi: 10.1371/journal.pone.0062855 (2012).

33. Annilo, T., Kepp, K. \& Laan, M. Natural antisense transcript of natriuretic peptide precursor A (NPPA): structural organization and modulation of NPPA expression. BMC molecular biology 10, 81, doi: 10.1186/1471-2199-10-81 (2009).

34. Ichiyama, K. et al. The methylcytosine dioxygenase Tet2 promotes DNA demethylation and activation of cytokine gene expression in T cells. Immunity 42, 613-626, doi: 10.1016/j.immuni.2015.03.005 (2015).

35. Muto, H. et al. Reduced TET2 function leads to T-cell lymphoma with follicular helper T-cell-like features in mice. Blood cancer journal 4, e264, doi: 10.1038/bcj.2014.83 (2014).

36. Shelley, C. S. et al. Molecular characterization of sialophorin (CD43), the lymphocyte surface sialoglycoprotein defective in WiskottAldrich syndrome. Proceedings of the National Academy of Sciences of the United States of America 86, 2819-2823 (1989).

37. Pedraza-Alva, G. et al. CD43 regulates the threshold for T cell activation by targeting Cbl functions. IUBMB life 63, 940-948, doi: 10.1002/iub.554 (2011).

38. Tan, E. M. et al. The 1982 revised criteria for the classification of systemic lupus erythematosus. Arthritis and rheumatism 25, 1271-1277 (1982).

39. Bombardier, C., Gladman, D. D., Urowitz, M. B., Caron, D. \& Chang, C. H. Derivation of the SLEDAI. A disease activity index for lupus patients. The Committee on Prognosis Studies in SLE. Arthritis and rheumatism 35, 630-640 (1992).

40. Schmitt, N. et al. The cytokine TGF-beta co-opts signaling via STAT3-STAT4 to promote the differentiation of human TFH cells. Nature immunology 15, 856-865, doi: 10.1038/ni.2947 (2014).

\section{Acknowledgements}

This work was supported by the National Natural Science Foundation of China (No. 81210308042, No. 81430074, No. 81220108017 and No. 30972745), the programs of Science-Technology Commission of Hunan province (2011FJ2007, 2011TP4019-7, 2012WK3046 and 2012TT2015), the Fundamental Research Funds for the Central Universities and the National Key Clinical Specialty Construction Project of National health and Family Planning Commission of the People's Republic of China. Principal recipient of the funding listed above is Prof. Qianjin Lu. We would like to thank Bruce C. Richardson and Amr H. Sawalha, from the Division of Rheumatology, University of Michigan for their critical reading and suggestions for the manuscript. We would also like to recognize and give appreciation to all of our patients with systemic lupus erythematosus from Second Xiangya hospital for donating blood samples. We are grateful to the healthy-control volunteers. We also appreciate the support and assistance of the Dermatology team at Second Xiangya hospital of Central South University.

\section{Author Contributions}

H.W. designed and performed the experiments, analyzed the data, and wrote the manuscript; X.H. and H.Q. performed the Tfh cell differentiation, Chip-QPCR, western blot and transfection; W.L. performed the dot plot; S.Y. helped with the pathological analysis; Y.X. helped with human sample recruitment; M.Z., Y.D. and A.Y. helped with experimental design; C.C. helped with manuscript editing; and Q.L. initiated and secured funding for this project, helped with experimental design and data interpretation, and wrote the manuscript. 


\section{Additional Information}

Competing financial interests: The authors declare no competing financial interests.

How to cite this article: $\mathrm{Wu}, \mathrm{H}$. et al. High salt promotes autoimmunity by TET2-induced DNA demethylation and driving the differentiation of Tfh cells. Sci. Rep. 6, 28065; doi: 10.1038/srep28065 (2016).

(c) (i) This work is licensed under a Creative Commons Attribution 4.0 International License. The images or other third party material in this article are included in the article's Creative Commons license, unless indicated otherwise in the credit line; if the material is not included under the Creative Commons license, users will need to obtain permission from the license holder to reproduce the material. To view a copy of this license, visit http://creativecommons.org/licenses/by/4.0/ 